\title{
Selected Sex Related Differences in Pathophysiology of Cardiovascular System
}

\author{
Otomar KITTNAR ${ }^{1}$ \\ ${ }^{1}$ Institute of Physiology of the First Faculty of Medicine, Charles University, Prague, Czech \\ Republic
}

Received October 24, 2018

Accepted August 23, 2019

Epub Ahead of Print December 19, 2019

\section{Summary}

The annual incidence of cardiovascular diseases is agedependently increasing both in men and women, however, the prevalence is higher in men until midlife. The higher incidence of cardiovascular disease in men than in women of similar age, and the menopause-associated increase in cardiovascular disease in women, has led to speculation that gender-related differences in sex hormones might have a key role in the development and evolution of cardiovascular disease. There are several suggested pathways in which gender and sex hormones can affect human cardiovascular system to produce original sexually different pathophysiology between women and men. Sex steroid hormones and their receptors are critical determinants of cardiovascular gender differences. Also arterial blood pressure is typically lower in women than in men what could be explained particularly by greater synthesis of nitric oxide (NO) in women. Female cardiomyocytes have a greater survival advantage when challenged with oxidative stress, suggesting that female hormones may play an important role in antioxidative protection of myocardium. It was also demonstrated in animal models that combination of $\mathrm{XX}$ chromosomes versus an $\mathrm{XY}$ chromosomes enhances sex differences in higher HDL cholesterol. Women were found to have reduced sympathetic activity (reflected by lower total peripheral resistance) and pulmonary artery pressure and enhanced parasympathetic activity relative to men. Similarly, men were found to have higher plasma norepinephrine levels than women. Regarding differences between the sexes in electrophysiology of the heart, two principle mechanisms have been proposed to explain them: hormonal effects on the expression or function of ion channels or, conversely, differences in autonomic tone. To improve diagnosis and treatment of cardiovascular diseases, greater focus on understanding the molecular and cellular physiology of the sex steroid hormones and their receptors in the cardiovascular system will be required.

\section{Key words}

Sex related differences • Cardiovascular system • Sex hormones

\section{Corresponding author}

O. Kittnar, Institute of Physiology, First Medical Faculty, Charles University, Albertov 5, 12800 Prague 2, Czech Republic. E-mail: otomar.kittnar@staff.cuni.cz

\section{Introduction}

Cardiovascular diseases remain the primary cause of death worldwide. In the U.S.A., deaths due to cardiovascular disease for women surprisingly exceed those of men. On the other hand in middle-aged premenopausal women the incidence of cardiovascular disease is lower than in men (Levenson et al. 2002, Reckelhoff 2005). It means that women develop cardiovascular disease later in life than men. The higher incidence of cardiovascular disease in men than in women of similar age, and the menopause-associated increase in cardiovascular disease in women, has led to speculation that gender-related differences in sex hormones might have a key role in the development and evolution of cardiovascular disease (Armeni and Lambrinoudaki 2017). Compelling data have indicated that sex differences in vascular biology are determined not only by gender-related differences in sex steroid 
levels, but also by gender-specific tissue and cellular differences that mediate sex-specific responses. Cardiovascular cells contain functional estrogen, progesterone and androgen receptors and are targets for sex hormone action, which can influence many physiological and pathological processes, including vascular and myocardial cell homeostasis (Pierdominici et al. 2011). Gender disparity plays an important role in cardiovascular disease prevalence and burden with significant gender related differences reported in cardiovascular clinical presentation mortality, morbidity and risk factors profiles (Dantas et al. 2012). While cultural and psychosocial factors such as education, economic status, marital status and access to healthcare contribute to sex differences in adverse outcomes, physiological and molecular bases of differences between women and men that contribute to development of cardiovascular disease and response to therapy remain generally underexplored.

The effects of gender differences, including sex hormones, on cardiac and vascular cell injury and death and their influence in determining atherosclerosis, heart failure and other main human cardiovascular diseases started to be studied only recently. On the other hand, hormones are important but not unique actors in this issue, further genetic and epigenetic determinants being involved. Therefore, we need to derive some theories in order to suggest the best forecast, diagnosis, treatment and post-therapeutic prognosis with regard to differences between women and men what corresponds to the up to date approach of personalized medicine. The gene expression theory of human sex hormones modulating cardiovascular system could describe and explain most differences between women and men. The lower incidence of cardiovascular disease in middle-aged premenopausal women than in men and postmenopausal women has been attributed to the presence of female sex steroids in the circulation (Orshal and Khalil 2004).

\section{Possible pathogenetic mechanisms}

The mechanisms underlying these gender differences of the cardiovascular system pathophysiology between women and men can be explained by few different theories. In other words, there are several suggested pathways in which genetic sex itself and sex hormones can affect human cardiovascular system to produce original sexually different pathophysiology between women and men.

\section{Nitric oxide}

Sex steroid hormones and their receptors are supposed to be critical determinants of cardiovascular gender differences (Mendelsohn and Karas 2005). For instance, arterial blood pressure is typically lower in premenopausal women than in men what could be explained particularly by greater synthesis of nitric oxide (NO) in younger women (Forte et al. 1998). These sex differences are due partly to the well-known beneficial effects of estrogens, which include vasodilation thanks to upregulation of NO production in human endothelial cells and other cardiovascular protective functions (Chambliss and Shaul 2002, Yang et al. 2013). Logically numerous studies on human beings and also in animal models have dealt with a role of estrogens in cardiovascular protective functions. On the contrary the potential beneficial effects of progesterone have not been broadly acknowledged. Only recently progesterone has received more attention in studies performed on human beings (Pang et al. 2015, Nath and Sitruk-Ware 2009) and its protective effects on the cardiovascular system were simultaneously demonstrated in animal models (Chow et al. 2010, Roesch and Keller-Wood 1997). For instance, an activation pathway of the phosphoinositide 3-kinase/serine/threonine protein kinase (PI3K/AKT)dependent endothelial NO synthase (eNOS) was proved to protect the cardiovascular system. The mechanism of this progesterone effect is an increase of NO synthesis and eNOS phosphorylation in human vascular endothelial cells through activation of membrane progesterone receptor- $\alpha$ (Pang et al. 2015) what can effectively contribute to the blood pressure control. Thus, sex hormones can participate in rapid cellular activation pathways that either at least initially do not alter gene expression.

Functional steroid sex hormones receptors expressed in cardiovascular cells were already mentioned. But these receptors do not act alone, they interact with a broad array of regulatory proteins to alter transcription in target cells. Typical specific regulatory protein is coactivator 3 that is involved in mediating estrogen inhibition of vascular injury. In any case, most effects of sex hormones are based on gene expressions, for instance NO mediated vascular dilatation following activation of estrogen receptors (ERs): binding of estrogen to ERs leads to activation of gene expression of eNOS (Iorga et al. 2017). 


\section{Enzymes}

It has been reported that female cardiomyocytes have a greater survival advantage when challenged with oxidative stress, suggesting that female hormones may play an important role in antioxidative protection of myocardium (Knowlton and Lee 2012, Wang et al. 2010). This theory was confirmed by a large set of animal experiments:

1. Lagranha et al. (2010) showed that administration of estrogens attenuated the generation of reactive oxygen species and reduced apoptosis by suppressing ischemia/reperfusion (I/R) induced oxidative injury of myocardium. This cardioprotective effect of estrogens was found to be mediated by enhancing an expression of cystathionine- $\gamma$-lyase (CSE), an enzyme generating hydrogen sulfide $\left(\mathrm{H}_{2} \mathrm{~S}\right)$. As oxidative stress is considered one of the main causative factors in various cardiovascular disorders (Fearon and Faux 2009) this effect of estrogens seems to be extremely important.

2. Wang et al. (2015) proved that the CSE inhibitor or the CSE small interfering RNA attenuated the protective effect of $17 \beta$-estradiol against $\mathrm{H}_{2} \mathrm{O}_{2}{ }^{-}$and hypoxia/reoxygenation-induced injury in primary cultured neonatal cardiomyocytes. Moreover they demonstrated that estrogens stimulate CSE expression via estrogen receptor- $\alpha$ both in cultured cardiomyocytes in vitro and in the myocardium of female mice in vivo.

3. In fact, this is not the only mechanism underlying the fact that pre-menopausal women are better protected against ischemia/reperfusion-induced oxidative injury of myocardium. Female hearts have also increased phosphorylation and activity of aldehyde dehydrogenase, an enzyme that detoxifies reactive oxygen species (ROS) and thus myocytes from female hearts had less ROS generation following ischemia/reperfusion process than male myocytes (Claudia et al. 2010).

Activation of estrogen receptors (ERs) on the mitochondrial membrane in cardiomyocytes leads to maintenance of mitochondrial hemostasis, cell survival and cardioprotection. The mechanism of cardioprotection lies in phosphorylation of aldehyde-dehydrogenase 2 resulting in its increased activity and thus in protection of the heart against ischemic damage (Iorga et al. 2017).

4. Another recent animal study on female mice suggested anti-fibrotic effect of estrogen in the heart by blocking the pro-fibrotic effects of angiotensin II and endothelin-1 on metalloproteinases (MPs) (Pedram et al. 2016). Hereby estrogen prevents enzymatic digestion of myocardial extracellular matrix by MPs that would lead to imbalance of collagen deposition and thus to cardiac remodeling.

\section{Sex chromosomes}

Like autosomal chromosomes, the sex chromosomes (ChrX; ChrY) are thought to have once been identical pairs that were free to recombine and exchange genetic material. Over the course of evolution, ChrY became unique from all other chromosomes with the acquisition of a dominant sex-determining gene and subsequent chromosomal inversions that restricted recombination with its homologous $\mathrm{ChrX}$ that led to its degradation. The relatively few protein-coding genes on ChrY are predominantly male-specific genes acquired through transposition and translocation from other chromosomes. Some authors indicate that a locus/loci on the Y chromosome may influence LDL levels independently of testosterone levels (Charchar et al. 2004). Other authors also demonstrate in animal models that combination of XX chromosomes versus an XY chromosomes enhances sex differences in higher HDL cholesterol. It is conceivable that increased expression of genes escaping $\mathrm{X}$-inactivation in $\mathrm{XX}$ mice regulates downstream processes to establish sexual dimorphism in plasma lipid levels (Link et al. 2015). Following menopause, the lipid profile of females becomes more atherogenic and is correlated with the higher incidence of heart disease in that population. As a consequence, there has been considerable interest in the potential role of sex hormones in atherogenesis, particularly the potential protective effects of female gender. Over the last decade, compelling evidence has emerged that sex differences in vascular biology are not only determined by gender-related differences in sex steroid levels but also by gender-specific tissue and cellular characteristics which mediate sex-specific responses to a variety of stimulation. Moreover, it was suggested that genes located on the $\mathrm{Y}$ chromosome are associated with the renin-angiotensin-aldosterone system (RAAS) (Sampson et al. 2014). It seems to be proved that the Y chromosome significantly impacts the renal vascular responsiveness and therefore may influence the long-term renal regulation of blood pressure. In addition to Y-linked genes also X-linked genes associated with the RAAS were described (Li et al. 2014). While polymorphisms of X-linked genes could play an independent leading role in determining susceptibility to arterial hypertension in both genders (Li et al. 2014), the genetic lineage from which the $\mathrm{Y}$ chromosome 
originates, whether it is inherited from a hypertensive or normotensive father, plays an integral role in men (Sampson et al. 2014).

\section{Hypothalamic-pituitary-adrenal axis (HPA)}

Interactions between the gonadal hormone system and the HPA belong to the key mediators of many sex differences, as mechanisms causing sexual dichotomies involve a confluence of neural and peripheral circuits leading to greater glucocorticoid release in females (Goel et al. 2014). Systems impinging on the HPA axis that contribute to these sex differences include the monoamine neurotransmitters norepinephrine and serotonin. More synthesis and faster replenishment of stress peptide stores are typical for females, while higher activity of limbic inhibitory pathways is characteristic for males. Diverse signals originating from the brain and periphery are integrated to determine the level of HPA activity, and these signals are, in many cases, sexspecific thanks to negative feedbacks impacted by gonadal hormones. This is the pathway by which androgens increase and estrogens decrease an activity of the HPA axis (Goel et al. 2014). As sex hormones act as neuroactive steroids regulating the function of neuroendocrine diencephalic structures like the hypothalamus, they can exert differential effects on a variety of sensitive tissues. While their role in extrahypothalamic areas related to memory, motivated behaviors, learning, and locomotion has been the focus of much research, the effects of sex hormones on the neurochemical regulation of cardiovascular system only start to be studied. Recent studies of blood pressure control and cardiac function in healthy men and women have demonstrated that women and men use the two arms of the baroreflex system differently. At all ages, women were found to have reduced sympathetic activity (reflected by lower total peripheral resistance) and pulmonary artery pressure and enhanced parasympathetic activity relative to men. Similarly, men were found to have higher plasma norepinephrine levels than women (Geelen et al. 2002).

\section{A role of diabetes}

It is not necessary to emphasize that diabetes is one of crucial risk factors in cardiovascular morbidity and mortality and so sex related differences in glucose metabolism can be also very interesting from this point of view. Males appear to be at greater risk of diabetes at younger age and at lower body mass index (BMI) compared to women, but women feature a dramatic increase of their cardio-metabolic risk after menopause (Stuenkel 2017). Pre-diabetic and diabetic women are at much higher relative risk for vascular disease. Women are more often obese and less physically active, but may even have greater benefit from increased physical activity than males. Whereas men predominantly feature impaired fasting glucose, women often show impaired glucose tolerance. A history of gestational diabetes or the presence of a polycystic ovary syndrome or increased androgen levels in women, on the other hand the presence of erectile dysfunction or decreased testosterone levels in men are sex specific risk factors for diabetes development. Several studies showed that diabetic women reach their targets of metabolic control glycated hemoglobin, blood pressure and low-density lipoproteincholesterol less often than their male counterparts, although the reasons for worse treatment outcome in diabetic females are not clear (Kautzky-Willer et al. 2016). Estrogens receptors regulate various aspects of glucose and lipid metabolism. Disturbances of this metabolic signal lead to the development of metabolic syndrome and a higher cardiovascular risk in women. The absence of estrogens is a clue factor in the onset of cardiovascular disease during the menopausal period, which is characterized by lipid profile variations and predominant abdominal fat accumulation. Sex hormones generally influence body fat distribution and adipocyte differentiation. Estrogens regulate various aspects of glucose and lipid metabolism and the absence of estrogens has a significant effect on obesity in menopausal women as it leads to the development of metabolic syndrome and a higher cardiovascular risk (Lizcano and Guzman 2014). Thus, estradiol and their receptors in the hypothalamus play a key role in metabolic syndrome development during menopause.

\section{A role of inflammation and thrombosis}

Some interesting sex related differences were observed in pathogenesis of coronary atherosclerosis. Endogenous and particularly exogenous sex hormones influence fat distribution/deposition, insulin resistance, lipid metabolism, coagulation factors, and inflammation measured by high sensitivity C-reactive protein (Bairey Merz et al. 2006). For instance, inflammatory processes increase anticardiolipin antibodies, which are more prevalent in women. Reduced NO synthesis, increased endothelium permeability and expression of proteins required for adhesion of inflammatory cells are processes 
modulated by sex hormones (Fortini et al. 2019). Estrogen is promoting eNOS activation and limiting the expression of proteins involved in monocytes and neutrophils adhesion to the endothelial monolayer and thereby preventing the migration of leukocytes to the subendothelial space and their subsequent production of inflammatory cytokines (Cossette et al. 2013). Women appear to have more diffuse atherosclerosis, less luminal stenosis, higher incidence of endothelial dysfunction, and a higher prevalence of microvascular dysfunction than men (Shaw et al. 2006, Bairey Merz et al. 2006). Protective effect of estrogens on endothelial function seems to be related to an influence of the shear stress on the endothelial function (Holder et al. 2019). The pathoanatomic substrate for coronary thrombosis also differs between men and women. In men, $80 \%$ of coronary thrombi tend to occur because of plaque rupture, whereas in women, 20-40\% of coronary thrombi occur on an intact atherosclerotic plaque with superficial atherointimal erosion (Burke et al. 1998, Farb et al. 1996). This plaque erosion is a common finding in sudden cardiac death in younger women who were smokers and postmenopausal women taking hormone replacement therapy.

Sudden death was reported in $40 \%$ of the men and $34 \%$ of the women with ischemic artery disease. The incidence of sudden death is low in subjects of both sexes under 45 years. Above this age, the incidence doubles with each additional decade of life, starting 20 years later in women. A history of myocardial infarction increases the risk of sudden death by 4 in men and by 3 in women. Ten years after the infarction, the risk of sudden death is $5.3 \%$ in women and $11.9 \%$ in men (Kannel et al. 1998).

\section{$\mathrm{Ca}^{2+}$ handling in cardiomyocytes}

The ability to recognize and appreciate from a reproductive standpoint that males and females possess different attributes has been long standing. Only more recently we have begun to look more deeply into both the similarities and differences between men and women with respect to the structure and function of different organ systems. Recognizing the differences between the sexes with respect to cardiovascular function facilitates understanding of the mechanisms whereby homeostasis can be achieved using different contributions or components of the living system. Furthermore, recognition of the differences as well as the similarities permits the design of appropriate diagnostic instruments, recognition of sex-specific pathophysiology and implementation of appropriate treatment of cardiovascular disease in men and women.

Sex differences at several different locations in the excitation-contraction (E-C) coupling pathway have been implicated. Most notably, new studies have shown that cardiomyocytes from female hearts exhibit a marked decrease in the gain of E-C coupling, which translates to a decrease in sarcoplasmic reticulum (SR) $\mathrm{Ca}^{2+}$ release. This has been observed as lower peak $\mathrm{Ca}^{2+}$ transients and smaller individual $\mathrm{SR} \mathrm{Ca}^{2+}$ sparks in myocytes from females, in comparison to males (Parks and Howlett 2013). Moreover, myocardial contractile function is modified also by testosterone, with a focus on the impact of testosterone on processes that regulate $\mathrm{Ca}^{2+}$ handling at the level of the ventricular myocyte. The idea that testosterone regulates $\mathrm{Ca}^{2+}$ handling in the heart is important, as $\mathrm{Ca}^{2+}$ dysregulation plays a key role in the pathogenesis of a variety of different cardiovascular diseases (Ayaz and Howlett. 2015). Therefore, female myocytes have smaller contractions in comparison to males. Contractions are also slower to relax in female myocytes, which is likely a result of reduced $\mathrm{SR} \mathrm{Ca}^{2+}$ uptake via SERCA. Oophorectomy causes a marked increase in the gain of E-C coupling, resulting in larger peak $\mathrm{Ca}^{2+}$ transients and larger $\mathrm{Ca}^{2+}$ sparks what suggest that estrogens suppress $\mathrm{SR} \mathrm{Ca}^{2+}$ release and contributes importantly to the reduction in EC coupling gain present in cardiomyocytes from females. Oophorectomy also promotes cardiomyocyte $\mathrm{Ca}^{2+}$ dysregulation, including elevated SR $\mathrm{Ca}^{2+}$ content and larger unitary $\mathrm{Ca}^{2+}$ release events. This $\mathrm{SR} \mathrm{Ca}^{2+}$ overload promotes the spontaneous release of $\mathrm{Ca}^{2+}$ from the $\mathrm{SR}$. This could increase susceptibility to a range of different cardiovascular diseases in low estrogen states, such as in postmenopausal women. This is consistent with evidence that oophorectomy increases action potential duration in individual myocytes in animal models. This may be clinically important as prolongation of the action potential can increase the probability of early RonT depolarizations, which can trigger arrhythmias such as torsades des pointes.

\section{Controversies of estrogen's cardioprotective effect}

Many mechanisms underlying possible cardioprotective effect of female hormones were already mentioned in the previous paragraphs. On the other hand, while postmenopausal women are at greater risk than 
premenopausal women regarding cardiovascular mortality, the incidence of cardiovascular diseases is still significantly lower in postmenopausal women compared to age-matched men (Arnold et al. 2017). Furthermore, at this age, the risk of a first incident coronary heart disease is higher in men while the risk of a first incident cerebrovascular disease or heart failure is higher in women. It indicates that the cardioprotection conferred by estrogens is more complex than it was supposed and that more factors in addition to female hormones must be taken into account (Fig. 1).

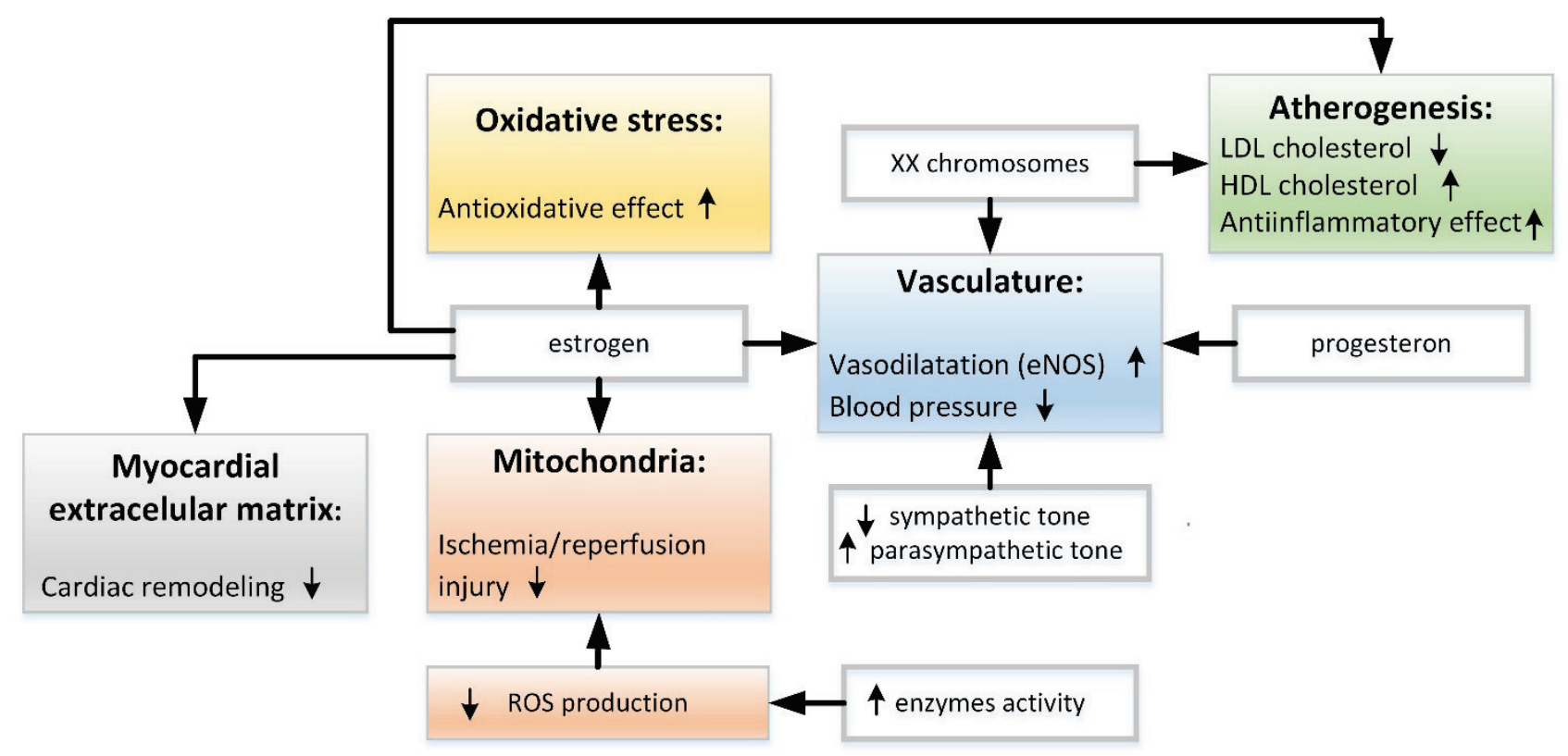

Fig. 1. Main pathways of cardioprotective mechanisms in women (see more details in the text).

Moreover, hormone replacement therapy (HRT) in postmenopausal women is at least controversial (Menazza and Murphy 2016). While the use of estrogen therapy has shown beneficial effects on cardiovascular diseases in animal models, large-scale randomized clinical trials designed to study the efficacy of hormonal replacement therapy in reducing the risk of coronary artery disease in postmenopausal women have completely failed (Grady et al. 2002) particularly due to adverse cardiovascular events and increased risk of breast cancer. This failure could be at least in part due to the HRT being administered long after the onset of menopause in most of the women enrolled (Arnold et al. 2017). A new hypothesis called "Critical window of hormone therapy" suggests that the HRT is effective if started as early as possible at the onset of menopause (Maki 2013).

\section{Electrophysiology of the heart}

Sex differences in cardiac repolarization and the arrhythmogenic risk of patients with inherited and acquired long-QT syndromes (LQTS) are well appreciated clinically. Female sex is a risk factor for both inherited and acquired LQTS and uses to be associated with higher incidence of arrhythmic events, particularly torsade de pointes, in women (Locati et al. 1998, Schwartz et al. 2006). On the other hand, women are less likely to experience ventricular tachycardia/ventricular fibrillation (VT/VF), and have fewer VT/VF episodes than men. Enhancing our knowledge of the mechanisms underlying these differences is critical to improve our therapeutic strategies for preventing sudden cardiac death. We can only speculate that the underlying mechanism is an effect of sex hormones on the expression and function of ion channels that control cardiac cell excitation and repolarization as well as on key proteins that regulate $\mathrm{Ca}^{2+}$ dynamics at the cellular level. These mechanisms could explain already proved role of sex hormones in modifying the dynamic spatiotemporal (regional and transmural) heterogeneities in action potential duration, e.g. the arrhythmogenic substrate (Odening and Koren 2014). The evidence from studies also published to date show that women have a higher mean resting heart rate, a longer QT interval, a shorter QRS duration, a lower QRS voltage, a shorter $\mathrm{P}$ wave duration, and shorter PR interval than men. 
Women have a higher prevalence of sick sinus syndrome, inappropriate sinus tachycardia, atrioventricular nodal reentry tachycardia, idiopathic right ventricular tachycardia, and arrhythmic events in the long-QT syndrome. In contrast, men have a higher prevalence of atrioventricular block, carotid sinus syndrome, atrial fibrillation, supraventricular tachycardia due to accessory pathways, Wolff-Parkinson-White syndrome, reentrant ventricular tachycardia, ventricular fibrillation and sudden death, and the Brugada syndrome (Bernal and Moro 2006). Two principle mechanisms have been proposed to explain these differences between the sexes: hormonal effects on the expression or function of ion channels or, conversely, sex related differences in autonomic tone. It is also possible that a combination of these two mechanisms may be involved. Sex hormones could regulate the expression of cardiac ion channels, for instance progesterone increases delayed rectifier $\mathrm{K}^{+}$current through the nitric oxide production pathway and prevents cyclic adenosine monophosphate enhancement of L-type $\mathrm{Ca}^{2+}$ current (Rosano et al. 1996). Other possible mechanisms are different distributions of ion channels between both sexes. This fact was described on animal experiments:

1. James et al. (2004) reported sex-related differences in ventricular myocyte repolarization in the guinea pig. They have found in their study that delayed rectifier $\mathrm{K}^{+}$current and inward rectifier $\mathrm{K}^{+}$current were different between sexes regardless of menstrual cycle.

2. Gaborit et al. (2010) further reported that male and female human hearts had significant differences in ion-channel subunit composition, with female hearts showing decreased expression of a number of repolarizing ion-channels.

The autonomic nervous system could also play the role. Autonomic regulation, contributing to different cardiac electrophysiology (Kapa et al. 2010, Yang et al. 2013) might explain gender differences in various arrhythmias (Dart et al. 2002, Hu et al. 2009, Morillo et al. 1994). Also idiopathic ventricular outflow tract ventricular tachycardias (RVOT-VT) were proved to have significant differences in electrophysiological characteristics between sexes (Yang et al. 2014). Ran et al. (2010) documented that Arg16Gly polymorphism in the ADRB2 gene encoding the $\beta 2$-adrenoceptor is significantly associated with RVOT-VT, which suggests a possible role of sympathetic system in this type of arrhythmia. In summary, gender differences might be attributed to multiple factors.
Not only the duration of repolarization is different in women, the so-called nonspecific repolarization changes in the 12-lead electrocardiogram are much more frequent in women. Similarly, the duration of the QT and QTc interval becomes shorter in men after puberty. The effects of estradiol and progesterone changes occurring in physiological menstrual cycle on ventricular premature beats (VPBs). VPB frequency is decreasing with estradiol peak in the ovulation period. This suggests that estrogen may have protective effects against ventricular arrhythmias (Dogan et al. 2016). Again, hormonal influences on the membrane ion channels, autonomic tone or a combination of these factors may all play a role. A combined mechanism would lead to greater sympathetic activity and a lower baroreflex response in men of any age as well as to more pronounced parasympathetic or vagal activity in women.

Some reports have shown that women may obtain greater benefit than men from cardiac resynchronization therapy (CRT). CRT is an established therapy for symptomatic patients with heart failure, a reduced left ventricular ejection fraction, and electrical dyssynchrony (Kittnar et al. 2017). However, the reason for the sex related difference in CRT outcome is not yet fully clarified. One option could be shorter QRS complex in women as the QRS duration is supposed to predict a success rate of CRT. Another possibility is a difference in the cause of electrical dyssynchrony: left bundle branch block (LBBB) is known as a cause of electrical dyssynchrony that is associated with greater benefit from CRT (Linde et al. 2018) and as LBBB is more prevalent in women, this might also explain differences in the effect of CRT between the sexes.

\section{Future tasks}

To improve diagnosis and treatment of cardiovascular diseases and adjust them to a concept of personalized medicine, it will be necessary to strengthen interactions between preclinical and clinical scientists in cardiophysiology and cardiology (Mendelsohn and Karas 2005). Only such approach could improve our understanding of the biology of gender differences and of the perimenopause, and reconsider the paradigm of and singular focus on untailored postmenopausal hormonal replacement therapy that has dominated the past several decades. To accomplish these goals, greater focus on understanding the molecular and cellular physiology of 
each of the sex steroid hormones and their receptors in the cardiovascular system will be required. Sex differences suggest that biomedical principles, learned from the study of males, may not apply equally to females. When studying cardiovascular diseases, the two genders must be directly compared, with the purpose of finding factors that cause sex differences and, therefore, prevent or alleviate disease in one sex more than the other (Arnold et al. 2017).

\section{Acknowledgements}

Supported by Progres Q41.

\section{References}

ARMENI E, LAMBRINOUDAKI I: Androgens and cardiovascular disease in women and men. Maturitas 104: 54-72, 2017. https://doi.org/10.1016/j.maturitas.2017.07.010

ARNOLD AP, CASSIS LA, EGHBALI M, REUE K, SANDBERG K: Sex hormones and sex chromosomes cause sex differences in the development of cardiovascular diseases. Arterioscler Thromb Vasc Biol 37: 746-756, 2017. https://doi.org/10.1161/ATVBAHA.116.307301

AYAZ O, HOWLETT SE: Testosterone modulates cardiac contraction and calcium homeostasis: cellular and molecular mechanisms. Biol Sex Differ 6: 1-15, 2015. https://doi.org/10.1186/s13293-015-0027-9

BAIREY MERZ CN, SHAW LJ, REIS SE, BITTNER V, KELSEY SF, OLSON M, JOHNSON BD, PEPINE CJ, MANKAD S, SHARAF BL, ROGERS WJ, POHOST GM, LERMAN A, QUYYIMI AA, SOPKO G, WISE INVESTIGATORS: Insights from the NHLBI-Sponsored Women's Ischemia Syndrome Evaluation (WISE) Study: Part II: gender differences in presentation, diagnosis, and outcome with regard to gender-based pathophysiology of atherosclerosis and macrovascular and microvascular coronary disease. J Am Coll Cardiol 47 (3 Suppl): S21-S29, 2006. https://doi.org/10.1016/j.jacc.2004.12.084

BERNAL O, MORO C: Cardiac arrhythmias in women. Rev Esp Cardiol 59: 609-618, 2006. https://doi.org/10.1016/S1885-5857(07)60011-5

CHAMBLISS KL, SHAUL PW: Estrogen modulation of endothelial nitric oxide synthase. Endocr Rev 23: 665-686, 2002. https://doi.org/10.1210/er.2001-0045

CHARCHAR FJ, TOMASZEWSKI M, LACKA B, ZAKRZEWSKI J, ZUKOWSKA-SZCZECHOWSKA E, GRZESZCZAK W, DOMINICZAK AF: Association of the human Y chromosome with cholesterol levels in the general population. Arterioscler Thromb Vasc Biol 24: 308-312, 2004. https://doi.org/10.1161/01.ATV.0000113291.39267.0a

CHOW RW, HANDELSMAN DJ, NG MK: Minireview: rapid actions of sex steroids in the endothelium. Endocrinology 151: 2411-2422, 2010. https://doi.org/10.1210/en.2009-1456

CLAUDIA J, DESCHAMPS A, APONTE A, STEEBERGEN C, MURPHY E: Sex differences in the phosphorylation of mitochondrial proteins result in reduced production of reactive oxygen species and cardioprotection in females. Circ Res 106: 1681-1691, 2010. https://doi.org/10.1161/CIRCRESAHA.109.213645

COSETTE E, CLOUTIER I, TARDIF K, DONPIERRE G, TANGUAY JF: Estradiol inhibits vascular endothelial cells pro-inflammatory activation induced by C-reactive protein. Mol Cell Biochem 373: 137-147, 2013. https://doi.org/10.1007/s11010-012-1482-9

DANTAS AP, FORTES ZB, DE CARVALHO MH: Vascular disease in diabetic women: why do they miss the female protection? Exp Diabetes Res 2012: 570598, 2012. https://doi.org/10.1155/2012/570598

DART AM, DU XJ, KINGWELL BA: Gender, sex hormones and autonomic nervous control of the cardiovascular system. Cardiovasc Res 53: 678-687, 2002. https://doi.org/10.1016/S0008-6363(01)00508-9

DOGAN M, YIGINER O, UZ O, KUCUK U, DEGIRMENCIOGLU G, LSILAK Z, UZUN M, DAVULCU E: The effects of female sex hormones on ventricular premature beats and repolarization parameters in physiological menstrual cycle. Pacing Clin Electrophysiol 39: 418-426, 2016. https://doi.org/10.1111/pace.12821

FEARON IM, FAUX SP: Oxidative stress and cardiovascular disease: novel tools give (free) radical insight. J Mol Cell Cardiol 47: 372-381, 2009. https://doi.org/10.1016/j.yjmcc.2009.05.013 
FORTE P, KNEALE BJ, MILNE E, CHOWIENCZYK PJ, JOHNSTON A, BENJAMIN N, RITTER JM: Evidence for a difference in nitric oxide biosynthesis between healthy women and men. Hypertension 32: 730-734, 1998. https://doi.org/10.1161/01.HYP.32.4.730

FORTINI F, VIECELI DALLA SEGA F, CALICETI C, LAMBERTINI E, PANNUTI A, PEIFFER DS, BALLA C, RIZZO P: Estrogen-mediated protection against coronary heart disease: The role of the Notch pathway. J Steroid Biochem Mol Biol 189: 87-100, 2019. https://doi.org/10.1016/j.jsbmb.2019.02.008

GABORIT N, VARRO A, LE BOUTER S, SZUTS V, ESCANDE D, NATTEL S, DEMOLOMBE S: Gender-related differences in ion-channel and transporter subunit expression in non-diseased human hearts. J Mol Cell Cardiol 49: 639-646, 2010. https://doi.org/10.1016/j.yjmcc.2010.06.005

GEELEN G, LAITINEN T, HARTIKAINEN J, LANSIMIES E, BERGSTROM K, NISKANEN L: Gender influence on vasoactive hormones at rest and during a $70^{\circ}$ head-up tilt in healthy humans. J Appl Physiol (1985) 92: 1401-1408, 2002. https://doi.org/10.1152/japplphysiol.00548.2001

GOEL N, WORKMAN JL, LEE TT, INNALA L, VIAU V: Sex differences in the HPA axis. Compr Physiol 4: 1121-1155, 2014. https://doi.org/10.1002/cphy.c130054

GRADY D, HERRINGTON D, BITTNER V, BLUMENTHAL R, DAVIDSON M, HLATKY M, HSIA J, HULLEY S, HERD A, KHAN S, NEWBY LK, WATERS D, VITTINGHOFF E, WENGER N, HERS RESEARCH GROUP: Cardiovascular disease outcomes during 6.8 years of hormone therapy: heart and estrogen/progestin replacement study follow-up (HERS II) JAMA 288: 49-57, 2002. https://doi.org/10.1001/jama.288.1.49

HOLDER SM, BRISLANE Á, DAWSON EA, HOPKINS ND, HOPMAN MTE, CABLE NT, JONES H, SCHREUDER THA, SPRUNG VS, NAYLOR L, MAIORANA A, THOMPSON A, THIJSSEN DHJ, GREEN DJ: Relationship between endothelial function and the eliciting shear stress stimulus in women: changes across the lifespan differ to men. J Am Heart Assoc 8: e010994, 2019. https://doi.org/10.1161/JAHA.118.010994

HU X, WANG J, XU C, HE B, LU Z, JIANG H: Effect of oestrogen replacement therapy on idiopathic outflow tract ventricular arrhythmias in postmenopausal women. Arch Cardiovasc Dis 104: 84-88, 2011. https://doi.org/10.1016/j.acvd.2010.11.011

IORGA A, CUNNINGHAM CM, MOAZENI S, RUFFENACH G, UMAR S, EGHBALI M: The protective role of estrogen and estrogen receptors in cardiovascular disease and controversial use of estrogen therapy. Biol Sex Differ 8: 33, 2017. https://doi.org/10.1186/s13293-017-0152-8

JAMES AF, ARBERRY LA, HANCOX JC: Gender-related differences in ventricular myocyte repolarization in the guinea pig. Basic Res Cardiol 99: 183-192, 2004. https://doi.org/10.1007/s00395-003-0451-6

KANNEL WB, WILSON PW, D'AGOSTINO RB, COBB J: Sudden coronary death in women. Am Heart J 136: 205-212, 1998. https://doi.org/10.1053/hj.1998.v136.90226

KAPA S, VENKATACHALAM KL, ASIRVATHAM SJ: The autonomic nervous system in cardiac electrophysiology: an elegant interaction and emerging concepts. Cardiol Rev 18: 275-284, 2010. https://doi.org/10.1097/CRD.0b013e3181ebb152

KAUTZKY-WILLER A, ABRAHAMIAN H, WEITGASSER R, FASCHING P, HOPPICHLER F, LECHLEITNER $\mathrm{M}$ : Sex- and gender-aspects in regard to clinical practice recommendations for pre-diabetes and diabetes. Wien Klin Wochenschr 2: 151-158, 2016. https://doi.org/10.1007/s00508-016-0957-1

KITTNAR O, RIEDLBAUCHOVÁ L, TOMIS J, LOŽEK M, VALERIÁNOVÁ A, HRACHOVINA M, MLČEK M, HUPTYCH M, JANOUŠEK J, LHOTSKÁ L: Electrocardiographic outcome of resynchronization therapy. Physiol Res 66 (Suppl 4): S523-S528, 2017.

KNOWLTON AA, LEE AR: Estrogen and the cardiovascular system. Pharmacol Ther 135: 54-70, 2012. https://doi.org/10.1016/i.pharmthera.2012.03.007

LAGRANHA CJ, PEDRAM A, RAZANDI M, LEVIN ER: Estrogen prevents cardiomyocyte apoptosis through inhibition of reactive oxygen species and differential regulation of p38 kinase isoforms. J Biol Chem 281: 6760-6767, 2006. https://doi.org/10.1074/jbc.M511024200

LEVENSON JW, SKERRETT PJ, GAZIANO JM: Reducing the global burden of cardiovascular disease: the role of risk factors. Prev Cardiol 5: 188-199, 2002. https://doi.org/10.1111/j.1520-037X.2002.00564.X 
LI J, FENG M, WANG Y, LI Y, ZHANG Y, LI L, XIONG J, LU C, WANG B, CHENG Z, TANG B, NIU W: The relationship between three X-linked genes and the risk for hypertension among northeastern Han Chinese. J Renin Angiotensin Aldosteron Syst 16: 1321-1328, 2015. https://doi.org/10.1177/1470320314534510

LINDE C, CLELAND JGF, GOLD MR, CLAUDE DAUBERT J, TANG ASL, YOUNG JB, SHERFESEE L, ABRAHAM WT: The interaction of sex, height, and QRS duration on the effects of cardiac resynchronization therapy on morbidity and mortality: an individual-patient data meta-analysis. Eur J Heart Fail 39: 780-791, 2018. https://doi.org/10.1002/ejhf.1133

LINK JC, CHEN X, PRIEN C, BORJA MS, HAMMERSON B, ODA MN, ARNOLD AP, REUE K: Increased highdensity lipoprotein cholesterol levels in mice with XX versus XY sex chromosomes. Arterioscler Thromb Vasc Biol 35: 1778-1786, 2015. https://doi.org/10.1161/ATVBAHA.115.305460

LIZCANO F, GUZMAN G: Estrogen deficiency and the origin of obesity during menopause. Biomed Res Int 2014 : 1-11, 2014. https://doi.org/10.1155/2014/757461.

LOCATI EH, ZAREBA W, MOSS AJ, SCHWARTZ PJ, VINCENT GM, LEHMANN MH, TOWBIN JA, PRIORI SG, NAPOLITANO C, ROBINSON JL, ANDREWS M, TIMOTHY K, HALL WJ: Age- and sex-related differences in clinical manifestations in patients with congenital long-QT syndrome: findings from the International LQTS Registry. Circulation 97: 2237-2244, 1998. https://doi.org/10.1161/01.CIR.97.22.2237

MAKI PM: Critical window hypothesis of hormone therapy and cognition: a scientific update on clinical studies. Menopause 20: 695-709, 2013. https://doi.org/10.1097/GME.0b013e3182960cf8

MENAZZA S, MURPHY E: The expanding complexity of estrogen receptor signaling in the cardiovascular system. Circ Res 118: 994-1007, 2016. https://doi.org/10.1161/CIRCRESAHA.115.305376

MENDELSOHN ME, KARAS RH: Molecular and cellular basis of cardiovascular gender differences. Science 308 : 1583-1587, 2005. https://doi.org/10.1126/science.1112062

MORILLO CA, KLEIN GJ, THAKUR RK, LI H, ZARDINI M, YEE R: Mechanism of 'inappropriate' sinus tachycardia. Role of sympathovagal balance. Circulation 90: 873-877, 1994. https://doi.org/10.1161/01.CIR.90.2.873

NATH A, SITRUK-WARE R: Different cardiovascular effects of progestins according to structure and activity. Climacteric 12 (Suppl 1): 96-101, 2009. https://doi.org/10.1080/13697130902905757

ODENING KE, KOREN G: How do sex hormones modify arrhythmogenesis in long QT syndrome? Sex hormone effects on arrhythmogenic substrate and triggered activity. Heart Rhythm Society 11: 2107-2115, 2014. https://doi.org/10.1016/j.hrthm.2014.06.023

ORSHAL JM, KHALIL RA: Gender, sex hormones, and vascular tone. Am J Physiol Regul Integr Comp Physiol 286: R233-R249, 2004. https://doi.org/10.1152/ajpregu.00338.2003

PANG Y, DONG J, THOMAS P: Progesterone increases nitric oxide synthesis in human vascular endothelial cells through activation of membrane progesterone receptor- $\alpha$. Am J Physiol Endocrinol Metab 308: E899-E911, 2015. https://doi.org/10.1152/ajpendo.00527.2014

PEDRAM A, RAZANDI M, NARAYANAN R, LEVIN ER: Estrogen receptor beta signals to inhibition of cardiac fibrosis. Mol Cell Endocrinol 434: 57-68, 2016. https://doi.org/10.1016/j.mce.2016.06.018

PIERDOMINICI M, ORTONA E, FRANCONI F, CAPRIO M, STRAFACE E, MALORNI W: Gender specific aspects of cell death in the cardiovascular system. Curr Pharm Des 17: 1046-1055, 2011. https://doi.org/10.2174/138161211795656891

PARKS RJ, HOWLETT SE: Sex differences in mechanisms of cardiac excitation-contraction coupling. Pflugers Arch 465: 747-763, 2013. https://doi.org/10.1007/s00424-013-1233-0

RAN YQ, LI N, YANG Y, CHEN JZ, FENG L, ZHANG S, PU JL: Beta2-adrenoceptor gene variant Arg16Gly is associated with idiopathic ventricular outflow-tract tachycardia. Chin Med J (Engl) 123: 2299-2304, 2010.

RECKELHOFF JF: Sex steroids, cardiovascular disease, and hypertension: unanswered questions and some speculations. Hypertension 45: 170-174, 2005. https://doi.org/10.1161/01.HYP.0000151825.36598.36

ROESCH DM, KELLER-WOOD M: Progesterone rapidly reduces arterial pressure in ewes. Am J Physiol Heart Circ Physiol 272: H386-H391, 1997. https://doi.org/10.1152/ajpheart.1997.272.1.H386 
ROSANO GMC, LEONARDO F, SARREL PM, BEALE CM, DE LUCA F, COLLINS P: Cyclical variation in paroxysmal supraventricular tachycardia in women. Lancet 347: 786-788, 1996. https://doi.org/10.1016/S0140-6736(96)90867-3

SAMPSON AK, ANDREWS KL, GRAHAM D, MCBRIDE MW, HEAD GA, THOMAS MC, CHIN-DUSTING JP, DOMINICZAK AF, JENNINGS GL: Origin of the $\mathrm{Y}$ chromosome influences intrarenal vascular responsiveness to angiotensin I and angiotensin (1-7) in stroke-prone spontaneously hypertensive rats. Hypertension 64: 1376-1383, 2014. https://doi.org/10.1161/HYPERTENSIONAHA.114.03756

SHAW LJ, BAIREY MERZ CN, PEPINE CJ, REIS SE, BITTNER V, KELSEY SF, OLSON M, JOHNSON BD, MANKAD S, SHARAF BL, ROGERS WJ, WESSEL TR, ARANT CB, POHOST GM, LERMAN A, QUYYIMI AA, SOPKO G, WISE INVESTIGATORS: Insights from the NHLBI-Sponsored Women's Ischemia Syndrome Evaluation (WISE) Study: Part I: gender differences in traditional and novel risk factors, symptom evaluation, and gender-optimized diagnostic strategies. J Am Coll Cardiol 47 (3 Suppl): S4-S20, 2006. https://doi.org/10.1016/i.jacc.2005.01.072

SCHWARTZ PJ, SPAZZOLINI C, CROTTI L, BATHEN J, AMLIE JP, TIMOTHY K, SHKOLNIKOVA M, BERUL CI, BITNER-GLINDZICZ M, TOIVONEN L, HORIE M, SCHULZE-BAHR E, DENJOY I: The Jervell and Lange-Nielsen syndrome: natural history, molecular basis, and clinical outcome. Circulation 113: 783-790, 2006. https://doi.org/10.1161/CIRCULATIONAHA.105.592899

STUENKEL CA: Menopause, hormone therapy and diabetes. Climacteric 20: 11-21, 2017. https://doi.org/10.1080/13697137.2016.1267723

WANG F, HE Q, SUN Y, DAI X, YANG XP: Female adult mouse cardiomyocytes are protected against oxidative stress. Hypertension 55: 1172-1178, 2010. https://doi.org/10.1161/HYPERTENSIONAHA.110.150839

WANG L, TANG ZP, ZHAO W, CONG BH, LU JQ, TANG XL, LI XH, ZHU XY, NI X: MiR-22/Sp-1 links estrogens with the up-regulation of cystathionine $\gamma$-lyase in myocardium, which contributes to estrogenic cardioprotection against oxidative stress. Endocrinology 156: 2124-2137, 2015. https://doi.org/10.1210/en.2014-1362

YANG SG, MLČEK M, KITTNAR O: Estrogen can modulate menopausal women's heart rate variability. Physiol Res 62 (Suppl 1): S165-S171, 2013.

YANG SG, MLCEK M, KITTNAR O: Gender differences in electrophysiological characteristics of idiopathic ventricular tachycardia originating from right ventricular outflow tract. Physiol Res 63 (Suppl 4): S451-S458, 2014. 